\title{
Longitudinal study of ventricular function after the Mustard operation for transposition of the great arteries: a long term follow up
}

\author{
KENG Y WONG, * ALEXANDER W VENABLES, * MICHAEL J KELLY, $\dagger$ \\ VICTOR KALFF†
}

From the ${ }^{\star}$ Department of Cardiology, Royal Childrens' Hospital, Melbourne, and the $\uparrow$ Nuclear Medicine Department, Alfred Hospital, Melbourne, Australia

SUMMARY An earlier study of 25 patients who were investigated by radionuclide angiography $\frac{\omega}{\sigma}$ after a Mustard procedure showed that they had had evidence of right and left ventricularo dysfunction at rest and with exercise. Twenty one (mean age 17.0 years (range 13.7-20.6) 11 femalepatients) of the original 25 patients were followed up a mean of 4.3 years later (mean 14.6 years요 (range 12.5-16.0) after the procedure). The group means for resting right and left ventricularo ejection fraction and exercise response were not significantly different from those reported five years before. Individual changes in values were within the normal variation seen in serial studies. $\vec{\varphi}$

This long term longitudinal follow up of patients after the Mustard operation showed that $\infty^{\infty}$ although some patients still had right and left ventricular dysfunction, resting ventricular function and exercise response remained stable over a five year period. This preservation of cardiac function may contribute to the long term survival of patients after the Mustard procedure.

Since 1964 when Mustard first reported his operation to correct transposition of the great arteries, ${ }^{1}$ cardiac centres throughout the world have performed this operation. Current mortality is low for uncomplicated cases ${ }^{2}$ but there has been concern about postoperative morbidity, including baffle obstruction, residual shunts, pulmonary venous obstructive disease, tricuspid regurgitation, arrhythmias, and right ventricular dysfunction. . $^{3-5}$

In 1984 Ramsay et al used radionuclide angiographic techniques to study ventricular function in a group who had had a Mustard procedure at the Royal Childrens' Hospital, Melbourne. ${ }^{6}$ We report a longitudinal follow up and update on this group of patients who we studied a mean of 4.3 years after the initial study and 14.6 years after their original operation.

\section{Patients and methods}

PATIENTS

In the earlier study 25 patients with Mustard's

Requests for reprints to Dr Alexander W Venables, Department of Cardiology, Royal Children's Hospital, Flemington Road, Melbourne, Victoria 3052, Australia.

Accepted for publication 14 March 1988 operation for D-transposition of the great arteries ${ }_{\circ}^{\mathbb{\Phi}}$ were investigated between August 1982 and March $\Rightarrow$ 1983. The clinical features of this group of patients 3 were described in the earlier paper. ${ }^{6}$

Since the first study four patients (cases $1,15,18,0$ and 23 in table 2 of Ramsay et al's paper') had implantation of pacemakers for management of sinus node dysfunction and one of these (case 18) died of right ventricular failure in 1985. Another (case 12) underwent an operation for obstruction of the superior vena cava after the completion of the first study and subsequently died of right ventricular failure before the start of the second study.

We reviewed the data on the two patients who had died in the interval between the two studies. The first (case 18) had an abnormal resting right ventricular $N$ ejection fraction by the equilibrium method but an normal first pass result. He also had no increase of ejection fraction at exercise by either method. The ${ }^{\omega}$ second (case 12) had abnormal right ventricular ejection fraction at rest with no increase at exercise by either method.

One patient (case 20) was lost to follow up, and another (case 22) refused consent for the study. We $e^{-}$ studied the remaining 21 patients between May 1986 and May 1987.

All the patients claimed to be symptom free and to음 
be leading normal lives with unrestricted physical activity at the time of the study. Their mean age was 17.0 years (range $13.7-20.6$ ) at the time of the second study which was performed a mean of 14.6 years (range 12.5 to 16.0) after operation. There were 10 male patients and 11 female patients and there were no significant sex differences in age or the interval since operation.

\section{Methods}

Twenty patients had electrocardiograms recorded and 19 had chest $x$ rays, 24 hour Holter monitor, and treadmill exercise tests according to the modified Bruce protocol. ${ }^{7}$ All 21 patients had a radionuclide study to measure right and left ventricular ejection fraction at rest and exercise (supine bicycle ergometer) by both the equilibrium and gated first pass techiques in the Department of Nuclear Medicine, Alfred Hospital, Melbourne, where the original tests were done. Details of these techniques were fully discussed in the earlier paper by Ramsay $e t$ $a l .6$ Imaging angles were adjusted for the rotation of the heart. In accordance with standard laboratory practice, ${ }^{8}$ the exercise workload was increased every three minutes instead of every four minutes as in the previous study. Apart from this, the equipment, technical aspects, and protocol were identical to the 1982 study.

The criteria for normal ejection fraction and exercise response were those used for the first study. ${ }^{69}$ Normal right ventricular ejection fraction was defined as $\geqslant 45 \%$ and left ventricular ejection fraction as $\geqslant 55 \%$. Normal exercise ejection fraction response was defined as an increase of $>5 \%$ from rest to maximal exercise or a value of $>75 \%$ at both rest and exercise. Others have reported similar values in children. ${ }^{9}$

For comparison with the previous study we excluded data on the four patients in whom the studies were not repeated.

\section{STATISTICAL ANALYSIS}

Values in the paper are mean (1 SD). We used the unpaired $t$ test to assess the significance of the sex differences for the workload and ventricular function. A paired $t$ test was used to compare the mean ventricular ejection fractions of the two studies. We used the coefficient of variation (defined as the standard deviation of (1982 ejection fraction minus 1987 ejection fraction) divided by the mean of 1982 ejection fraction) to assess the variability of the serial ejection fraction results.

\section{Results}

The mean cardiothoracic ratio for the 19 chest $x$ rays was $0.53(0.05)$.

The electrocardiograms showed that 12 of 20 patients had sinus rhythm, with five patients having a low atrial or junctional rhythm. Three had implanted pacemakers. Twenty four hour Holter monitor studies showed that five of 19 patients had normal sinus rhythm. In the others sinus rhythm alternated with low atrial and junctional rhythm (10 cases), atrioventricular dissociation (five cases), and/or frequent ventricular extrasystoles (two cases).

In the exercise treadmill test seven of 19 patients had exercise tolerance less than the 10th percentile for age and sex, seven patients were between the 10 th and 25 th percentile, and one was between the 25 th to 50 th percentile. Only four patients (cases $2,4,11$, and 25) had exercise tolerance above the 75th percentile. Three patients $(13,19$, and 23$)$ had frequent ventricular extrasystoles and two (cases 13 and 21) had ST depression of $1 \mathrm{~mm}$ during exercise which quickly became normal in the recovery phase.

\section{RESULTS OF SUPINE EXERCISE ON A BICYCLE ERGOMETER}

The mean heart rate at rest was $66(9)$ beats/min and at maximal exercise it was 130 (21) beats/min (an increase of $97 \%$ ). The mean systolic blood pressure at rest was 119 (6) $\mathrm{mm} \mathrm{Hg}$ and at maximal exercise it was 154 (17) $\mathrm{mm} \mathrm{Hg}$ (an increase of $29 \%$ ).

The mean maximal workload achieved at peak exercise was $1.68(0.34) \mathrm{W} / \mathrm{kg}$. There was a significant difference $(p \leqslant 0.001)$ between the mean maximal workload of the male patients $(1.93(0.21)$ $\mathrm{W} / \mathrm{kg})$ and of the female patients $(1.45(0.28) \mathrm{W} / \mathrm{kg})$. In the earlier study the mean maximal workload was $1.45(0.4) \mathrm{W} / \mathrm{kg}$. At that time there was no significant difference between the workload attained by the male patients $(1.58(0.49) \mathrm{W} / \mathrm{kg})$ and that obtained by the female patients $(1.32(0.29) \mathrm{W} / \mathrm{kg})$. Although the workload performance per kilogram body weight by the male patients improved significantly over the five year period ( $p<0.01)$, that of the female patients did not change significantly.

\section{RADIONUCLIDE DATA}

Table 1 shows the individual ejection fraction results. Figures 1-4 show the relation between the results obtained at this study and the results obtained in the earlier one.

Two out of 21 results for right ventricular ejection fraction measured by the equilibrium method could not be analysed. All right ventricular ejection fractions measured by first pass and all left ventricular ejection fractions by the equilibrium method were suitable for analysis. One left ventricular ejection fraction by first pass was not available for analysis because of bolus breakup. All 21 patients had their right and left ventricular ejection fractions measured 
Table 1 Right and left ventricular ejection fractions in 1987 (the results obtained in 1982 are given in parentheses)

\begin{tabular}{|c|c|c|c|c|c|c|c|c|c|}
\hline \multirow[b]{3}{*}{ Case No } & \multicolumn{4}{|c|}{ Right ventricular ejection fraction $(\%)$} & \multicolumn{4}{|c|}{ Left ventricular ejection fraction $(\%)$} & \multirow{3}{*}{$\begin{array}{l}\text { Workload } \\
(W / k g) \dagger\end{array}$} \\
\hline & \multicolumn{2}{|c|}{ Equilibrium study } & \multicolumn{2}{|c|}{ First pass study } & \multicolumn{2}{|c|}{ Equilibrium study } & \multicolumn{2}{|c|}{ First pass study } & \\
\hline & Rest & Exercise & Rest & Exercise & Rest & Exercise & Rest & Exercise & \\
\hline $\begin{array}{l}1 \\
2 \\
3 \\
4 \\
5 \\
6 \\
7 \\
8 \\
9 \\
10 \\
11 \\
12 \\
13 \\
14 \\
15 \\
16 \\
17 \\
18 \\
19 \\
20 \\
21 \\
22 \\
23 \\
24 \\
25\end{array}$ & $\begin{array}{l}28(44) \\
47(67) \\
\star \quad(\star) \\
59(32) \\
42(60) \\
57(49) \\
46(50) \\
50(33) \\
60(57) \\
59(52) \\
48(42) \\
48(38) \\
49(46) \\
40(43) \\
53(54) \\
\star(40) \\
\overline{1}(44) \\
55(48) \\
\overline{42}(44) \\
\frac{1}{4}(41) \\
45(61) \\
62(56) \\
56(60)\end{array}$ & $\begin{array}{l}38(57) \\
49(59) \\
\star \quad(\star) \\
48(48) \\
48(59) \\
65(55) \\
55(39) \\
51(40) \\
62(58) \\
54(59) \\
48(48) \\
47(39) \\
46(40) \\
25(35) \\
54(48) \\
\star(36) \\
-(41) \\
53(39) \\
48(56) \\
48(49) \\
44(37) \\
58(41) \\
65(54)\end{array}$ & $\begin{array}{l}42(56) \\
69(\star) \\
57(57) \\
59(46) \\
48(55) \\
72(72) \\
48(59) \\
50(55) \\
69(80) \\
51(57) \\
65(46) \\
-(44) \\
44(47) \\
62(38) \\
40(50) \\
58(56) \\
58(55) \\
54(54) \\
\frac{1}{5}(60) \\
60(59) \\
51(52) \\
62(70) \\
60(62)\end{array}$ & $\begin{array}{l}44(62) \\
69\left({ }^{\star}\right) \\
64(58) \\
69(61) \\
48(57) \\
78(65) \\
68(48) \\
61(70) \\
73(76) \\
56(42) \\
63(60) \\
-(42) \\
45(65) \\
53(51) \\
49(48) \\
57(63) \\
60(64) \\
61(54) \\
61(54) \\
65(60) \\
50(49) \\
50(53) \\
60(63) \\
55(60)\end{array}$ & 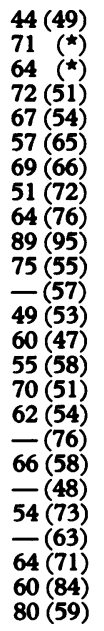 & $\begin{array}{l}40(52) \\
78(\star) \\
78(\star) \\
75(66) \\
63(53) \\
66(55) \\
75(71) \\
82(76) \\
63(81) \\
92(86) \\
77(66) \\
\overline{1}(72) \\
51(61) \\
55(51) \\
73(75) \\
81(66) \\
68(52) \\
\overline{76}(76) \\
76(68) \\
70(49) \\
\overline{70}(70) \\
61(74) \\
68(76) \\
90(81)\end{array}$ & $\begin{array}{l}64(65) \\
68\left({ }^{\star}\right) \\
61(57) \\
66(53) \\
59(52) \\
58(66) \\
67(63) \\
60(78) \\
83(78) \\
93(76) \\
74(56) \\
\overline{7}(62) \\
51(50) \\
\star(45) \\
78(\star) \\
55(75) \\
59(61) \\
\overline{73}(65) \\
73(53) \\
79(65) \\
6(72) \\
62(62) \\
69(72) \\
66(68)\end{array}$ & $\begin{array}{l}59(62) \\
75(\star) \\
76(67) \\
83(69) \\
69(57) \\
56(66) \\
66(75) \\
71(89) \\
88(91) \\
92(79) \\
91(79) \\
65(82) \\
\star(41) \\
80(\star) \\
77(73) \\
63(64) \\
88(69) \\
88(73) \\
79(78) \\
61(69) \\
61(65) \\
80(77) \\
75(80)\end{array}$ & $\begin{array}{l}2.0(1.7) \\
1.8(1.6) \\
1.4(1.2) \\
1.6(1.8) \\
1.9(0.9) \\
2.1(2.1) \\
1.5(1.4) \\
1.9(0.8) \\
1.9(1.8) \\
1.9(1.7) \\
1.9(2.2) \\
1.9(1.3) \\
2.1(2.1) \\
1.3(1.0) \\
1.6(1.1) \\
1.6(1.4) \\
1.3(1.0) \\
\frac{1}{2}(1.3) \\
2.2(1.3) \\
\frac{1}{1.1}(1.0) \\
1.1(1.2) \\
1.6(1.8)\end{array}$ \\
\hline
\end{tabular}

ॠTechnically unsatisfactory result; †peak workload/weight; - patients not restudied in 1987.

at rest and with exercise by either the first pass or equilibrium technique. The use of both equilibrium and first pass technique gave a better yield of results than use of either test alone. The difference in the values obtained by the two methods was discussed in the previous paper. ${ }^{6}$

There was no statistical difference in resting and exercise right and left ventricular ejection fraction $\stackrel{\varnothing}{\mathscr{\perp}}$ results by either method between the male and $\overrightarrow{\vec{P}}$ female patients.
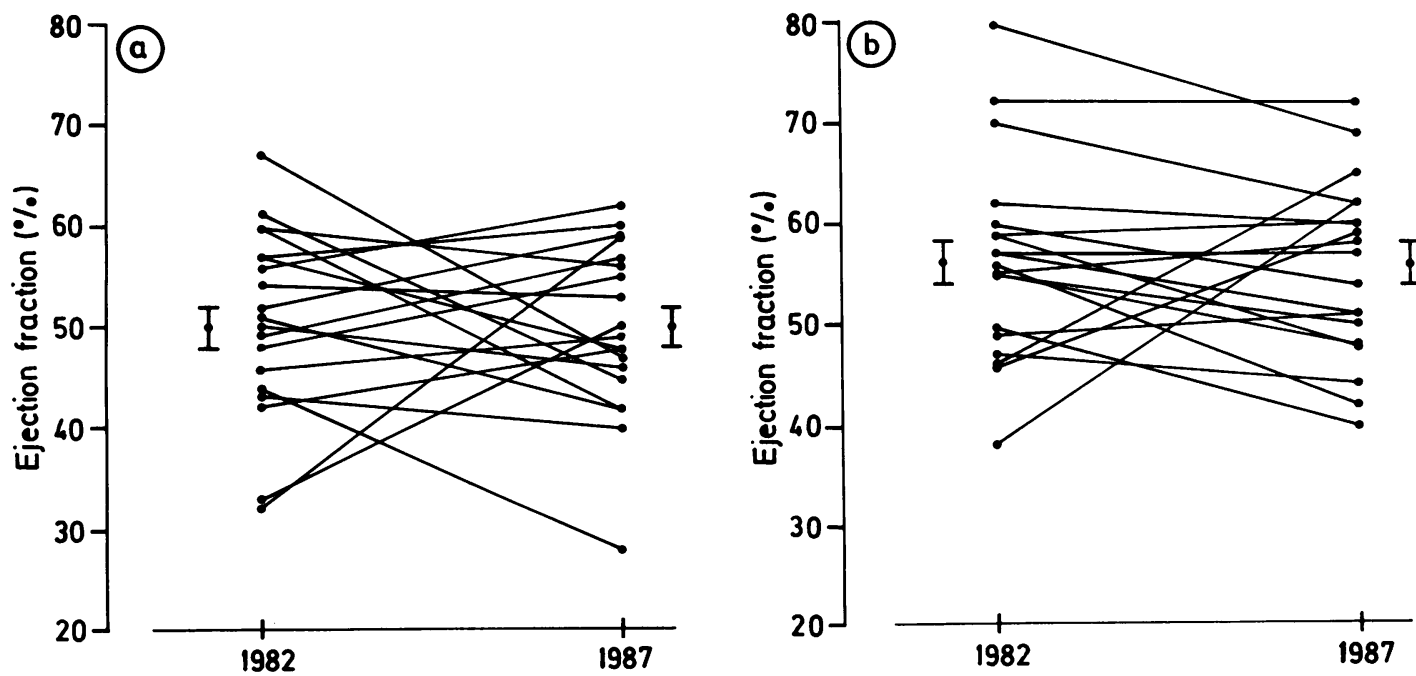

Fig 1 Individual right ventricular ejection fractions at rest and means (SEM) for 1982 and 1987 measured by (a) the equilibrium method and (b) the first pass method. 

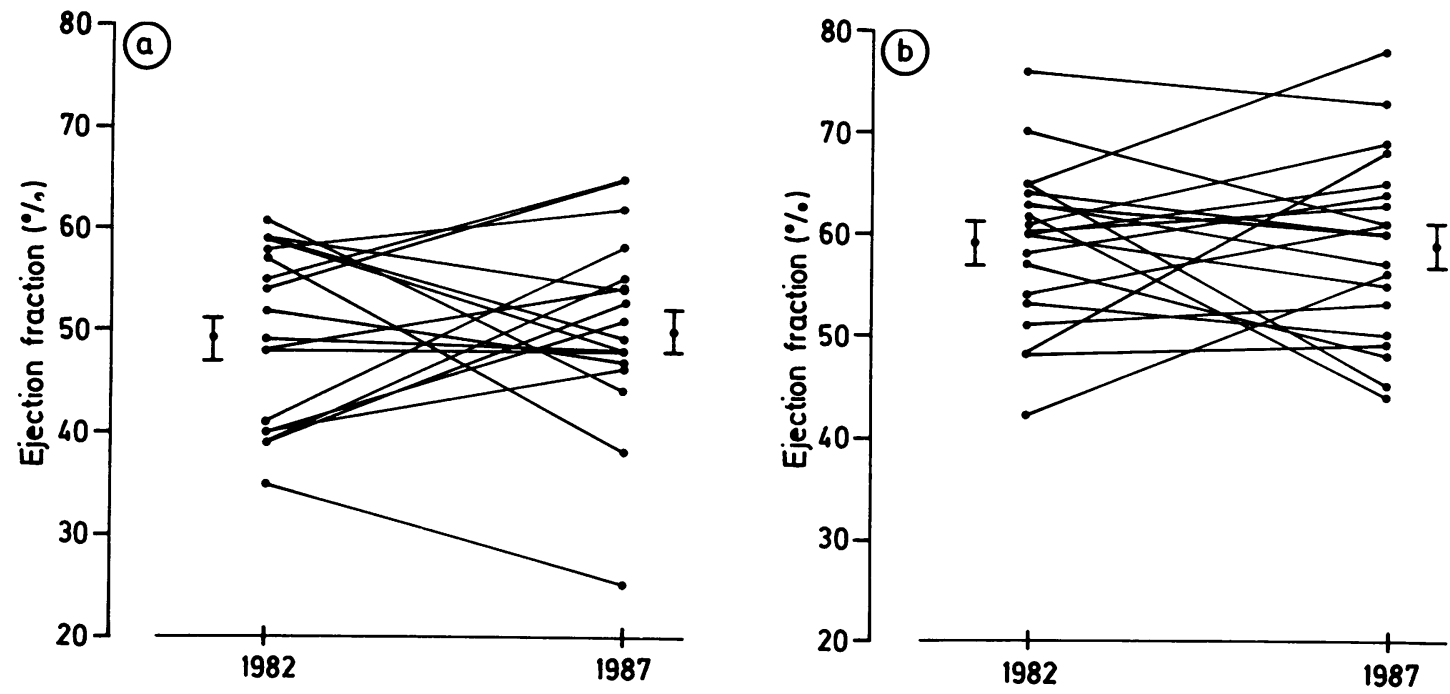

Fig 2 Right ventricular ejection fractions at maximal exercise and means (SEM) for 1982 and 1987 measured by (a) the equilibrium method and (b) the first pass method.
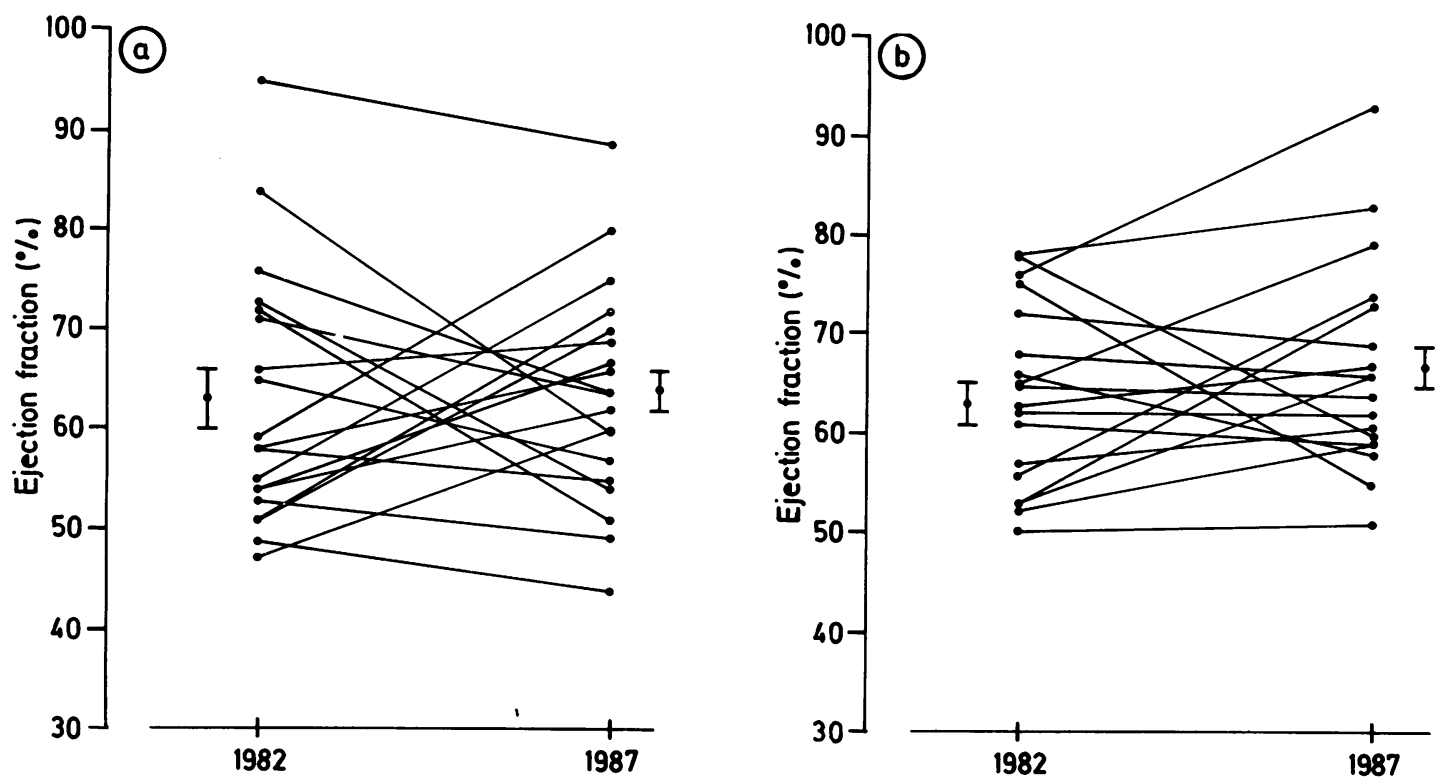

Fig 3 Left ventricular ejection fractions at rest and means (SEM) for 1982 and 1987 measured by (a) the equilibrium method and (b) the first pass method.

Right ventricular ejection fraction

The mean resting right ventricular ejection fractions by equilibrium and first pass were $50(8) \%$ and 56 (9)\% respectively and the mean exercise right ventricular ejection fractions by equilibrium and first pass were $\overline{50}(9) \%$ and $59(9) \%$ respectively (table 2$)$. The resting right ventricular ejection fraction was normal in $79 \%(15 / 19)$ of the patients by the equilibrium technique and in $86 \%(18 / 21)$ of patients by the first pass technique. The exercise response, 

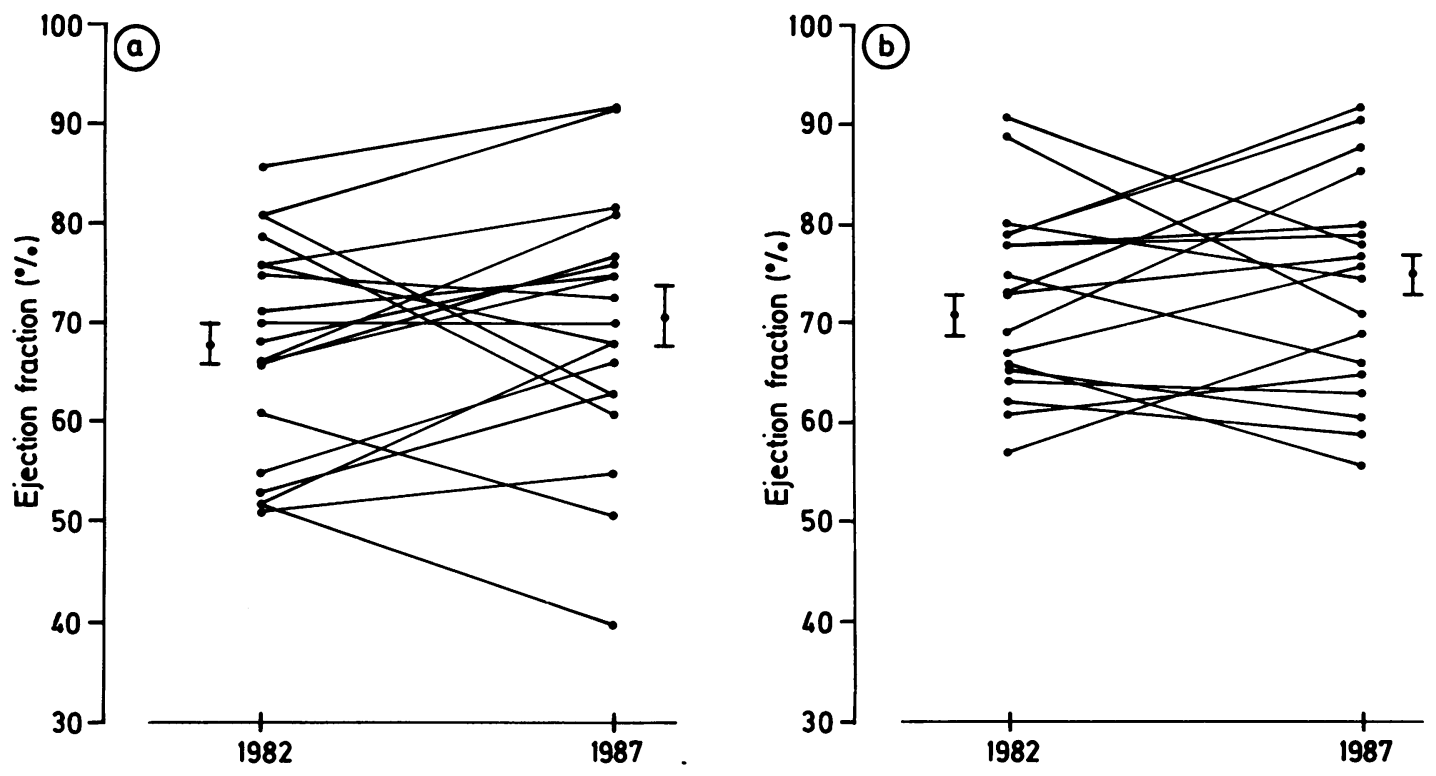

Fig 4 Left ventricular ejection fractions at maximal exercise and means (SEM) for 1982 and 1987 measured by (a) the equilibrium method and (b) the first pass method.

however, was normal in only $32 \%(6 / 19)$ of the patients by the equilibrium technique and $33 \%$ (7/ 21) of the patients by the first pass technique.

\section{Left ventricular ejection fraction}

The mean resting left ventricular ejection fractions by equilibrium and first pass were $64(11) \%$ and 67 (10)\% respectively and the mean exercise ejection fractions by the equilibrium and first pass techniques were $71(12) \%$ and $75(11) \%$ respectively. The resting left ventricular ejection fraction was normal in $81 \%(17 / 21)$ of patients by the equilibrium method and in $95 \%(19 / 20)$ of the patients by the first pass method. The left ventricular exercise response was normal in $67 \%(14 / 21)$ of the patients by the equilibrium techique and $75 \%(15 / 20)$ of the patients by the first pass technique.

\section{Serial ejection fraction measurements}

Table 2 shows the mean left and right ventricular ejection fractions of the two studies. Paired $t$ testing showed no significant change in the right or left ventricular ejection fraction at rest or execise by either method over the 4.3 year period (figs 1-4). Paired $t$ testing showed no significant change over $4 \cdot 3$ years in the response of the right or left ventricles to exercise (table 2).

Figures 1-4 show the variation in ejection fraction values between the initial and the follow up studies for all patients. To assess the possible significance of
Table 2 Mean (SD) ejection fraction values (\%)

\begin{tabular}{clllll}
\hline & \multicolumn{2}{l}{ Right ventricle } & & \multicolumn{2}{l}{ Left ventricle } \\
\cline { 6 - 6 } \cline { 5 - 6 } & Equilibrium & First pass & & Equilibrium & First pass \\
\hline Resting: & & & & \\
1987 study & $50(8)$ & $56(9)$ & $64(11)$ & $67(10)$ \\
1982 study & $50(9)$ & $56(10)$ & $63(13)$ & $63(10)$ \\
Exercise: & & & & \\
1987 study & $50(9)$ & $59(9)$ & $71(12)$ & $75(11)$ \\
1982 study & $49(9)$ & $59(8)$ & $68(11)$ & $71(11)$ \\
\hline
\end{tabular}

Table 3 Coefficients of variation for changes (\%) in ejection fraction seen in individual patients between 1982 and 1987

\begin{tabular}{llllll}
\hline & \multicolumn{2}{l}{ Right ventricle } & & \multicolumn{2}{l}{ Left ventricle } \\
\cline { 2 - 3 } & Equilibrium & First pass & & Equilibrium & First pass \\
\hline Resting & 23 & 18 & 24 & 18 \\
Exercise & 15 & 13 & 23 & 17 \\
\hline
\end{tabular}

the individual change in ejection fraction over this 4.3 year period we calculated the coefficients of $T$ variation between initial and follow up values for the $\bar{O}$ ejection fraction (table 3 ). These values were similar for the right and left ventricles, both at rest and during exercise. 


\section{Discussion}

We report a 4.3 year longitudinal follow up study of ventricular function at rest and exercise in a group of patients who had undergone the Mustard procedure a mean of 14.6 years earlier, and whose ventricular function had been previously studied by Ramsay et $a l .{ }^{6}$ Twenty one of the original 25 patients investigated by Ramsay et al were re-evaluated in the present study.

The electrocardiograms and 24 hour Holter monitor tapes showed evidence of sinus node dysfunction in most patients. Significant dysfunction requiring pacemaker implantation was seen in four patients. An increasing frequency of arrhythmias with time has been reported in patients with intraatrial repair for transposition of the great arteries in other follow up series. ${ }^{1011}$

The exercise tolerance of this group of patients on the treadmill was lower than in the normal population ${ }^{7}$ and was skewed towards the lower percentiles. This is consistent with the report by Mathews et al who found that despite their apparently normal clinical state, patients have subnormal exercise variables after the Mustard procedure. ${ }^{12}$ In the present study during the supine bicycle exercise test the male patients attained significantly higher workloads than the female patients, although five years before there were no differences between the sexes. Over the same five year period the male patients also had significant improvement of their workload performance compared with the first study while the female patients showed no change in their workload performance. It seems that the increased muscularity of the male patients during the adolescent growth period has led to their better workload performance. But the higher workload achieved by the boys had no bearing on ventricular ejection fraction-there was no significant difference in ventricular function between the sexes. Parrish et al found similar sex and age differences when they investigated ventricular function during exercise in normal children by a radionuclide technique."

As well as arrhythmias, another major concern in late follow up of patients after a Mustard procedure is how well the right ventricle can adapt to an increased afterload in its role as a systemic ventricle and whether its function will deteriorate with time. Cineangiography and radionuclide angiography of patients after the Mustard procedure showed evidence of right ventricular dysfunction. ${ }^{13-15}$

In this study the mean resting and exercise right ventricular function of the group remained unchanged over the period of 4.3 years. To assess the significance of individual changes in ventricular ejection fraction, we calculated the values of the coefficients of variation for individual changes in right ventricular rest and exercise ejection fraction between the present and previous study (table 3 ). We compared them with the values obtained from an earlier study done in this laboratory ${ }^{16}$ in which serial left ventricular ejection fraction measurements were examined over a period of several months. There are no other comparative studies of a group of patients studied by radionuclide angiography over a period of years. The coefficients of variation of the earlier study ranged from $16 \%$ to $26 \%^{16}$ and were thus comparable with those of the present study (table 3). Therefore, at this time, the differences in individual values could be accounted for by normal variation between serial studies.

The finding that overall right ventricular function at rest and at exercise was maintained and did not deteriorate during this interval is important. It suggests that any perioperative insult that damaged the myocardium was not progressive in this group of survivors for this period of follow up, and also that the right ventricle was able to cope as a systemic ventricle and provide a reasonable function over this period.

No other longitudinal study of similar patients is available for comparison. The results of Hurwitz et $a l,{ }^{17}$ however, accord with our findings. They measured the resting right ventricular ejection fraction by radionuclide techniques in three different sets of patients undergoing the Mustard procedure. One group was measured before the Mustard operation, one group 6-12 months after the Mustard procedure, and the last group three years after the Mustard procedure. They found no statistical difference in the mean resting right ventricular ejection fractions between the three groups, and these results also resembled those of their normal population. They proposed that the group right ventricular function did not deteriorate in a three year period after the Mustard procedure. Their conclusions could only be tentative because their study was not a longitudinal one and the length of follow up was relatively short.

Another group used as a model for comparison with patients after a Mustard procedure are patients with congenitally corrected transposition-that is where the morphologically right ventricle functions as the systemic ventricle. Parrish et al used radionuclide angiography in patients after a Mustard procedure and in congenitally corrected transposition and found no increase in right ventricular ejection fraction with exercise in either group. ${ }^{18}$ But the group they studied had associated cardiac abnormalities. Benson et al studied eight patients with congenitally corrected transposition without haemodynamically significant associated defects and reported that the mean systemic right ventricular 
ejection fraction was $48(4) \%$ at rest and $64(4) \%$ with exercise-that is a normal exercise response. ${ }^{19}$ Whether this is an appropriate model is debatable. None the less, the right ventricle was coping well as the systemic ventricle at the time of study in these patients with congenitally corrected transposition.

The present study also shows that left ventricular resting function and exercise response were also stable over the 4.3 years. Hence both the left and the right ventricles-that is the heart as a whole-did not show any change in functional state. This suggests that there was no progressive global damage to the myocardium.

Whereas most patients had normal resting right and left ventricular ejection fractions, in two thirds the response of the right ventricle to exercise was abnormal and in about one quarter the response of the left ventricle remained abnormal. The long term prognostic implications of these findings are unclear. A study by Bonow et al that examined left ventricular ejection fraction in adult patients with aortic incompetence suggested that an abnormal response to exercise may be predictive of progressive ventricular dysfunction. ${ }^{20}$ Bonow et al also found that patients who were apparently symptom free could have an abnormal cardiac reserve. ${ }^{20}$ Thus the apparent lack of correlation between clinical symptoms and abnormalities of ventricular contraction is not unique to patients with a Mustard repair. It is found in other patients with congenital heart disease. Del Torso et al showed a similar trend in children after a Fontan procedure. ${ }^{21}$ Further long term follow up studies are needed to assess the interrelations between abnormal exercise response, clinical symptoms, and prognosis after the Mustard procedure.

In conclusion, this longitudinal study on a group of patients after the Mustard procedure showed that right and left ventricular function at rest and exercise remained stable over a 4.3 year period that started at least eight years after the original operation. Evidence of ventricular dysfunction remained unchanged. The lack of progresson of myocardial dysfunction may contribute to the long term survival $^{22}$ and future outcome of patients after the Mustard procedure. However, this remains to be confirmed by further studies.

We thank Dr Rodney Hicks for performing some of the rest and exercise radionuclide ventriculographic studies.

\section{Addendum}

Since this paper was accepted for publication one patient has developed severe congestive heart failure. At follow up this patient (case 1 in table 1), showed the largest fall in both first pass and equilibrium right ventricular ejection fraction values and the lowest equilibrium left ventricular ejection fraction resules of any patient in this study. In infancy he had two direct operations for severe left ventricular outflow obstruction as well as secondary revision of the original Mustard operation, and in 1985 he required an implantation of a pacemaker because of atriog ventricular dissociation. He has been accepted for cardiac transplantation.

\section{References}

1 Mustard WT. Successful two stage correction of trans position of the great arteries. Surgery 1964;55:469-72:

2 Mahoney L, Turley, K, Ebert P, Heymann MA. Long term results after atrial repair of transposition of the great arteries in early infancy. Circulation 198\% 66:253-8.

3 Graham TP Jr. Hemodynamic residua and sequel\& following intraatrial repair of transposition of the great arteries. A review. Pediatr Cardiol 1982; 203-13.

4 Warnes CA, Somerville J. Transposition of the grea arteries: late results in adolescents and adults after tho Mustard procedure. Br Heart J 1987;58:148-55.

5 Stewart S, Alexson C, Manning J. Late results of the Mustard procedure in transposition of the gre arteries. Ann Thorac Surg 1986;42:419-24.

6 Ramsay JM, Venables AW, Kelly MJ, Kalff V. Riga and left ventricular function at rest and with exerci\$ after the Mustard operation for transposition of the great arteries. $\mathrm{Br}$ Heart $J$ 1984;51:364-70.

7 Cumming GR, Everrat D, Hastman L. Bruce treadmill test in children: normal values in clinic population Am J Cardiol 1978;41:69-75.

8 Berman DS, Maddahi J, Garcia EV, Freeman MP Shah PK. Assessment of left and right ventriculat function with multiple gated equilibrium cardiasf blood pool scintigraphy. In: Berman DS, Mansoü. DT, eds. Clinical nuclear cardiology. New York: Grune and Stratton, 1981:224-85.

9 Parrish MD, Boucek RJ Jr, Burger J, Artman MF Partain CL, Graham TP Jr. Exercise radionuclice ventriculography in children: normal values for exe cise variables and right and left ventricular function. Br Heart J 1985;54:509-16.

10 Flinn CJ, Wolff GS, Dick M, et al. Cardiac rhythm afte the Mustard operation for complete transposition the arteries. N Engl J Med 1984;310:1635-8.

11 Duster MC, Bink-Boelkens M Th E, Wampler ठ্ठ Gillette PC, McNamara DG, Cooley DA. Long term follow-up of dysrhythmias following the Mustaf procedure. Am Heart J 1985;109:1323-6.

12 Mathews RA, Fricker FJ, Beerman LB, et al. Exercise studies after the Mustard operation in transpositio $\$$ of the great arteries. Am J Cardiol 1983;51:1526-9.

13 Graham TP Jr, Atwood GF, Boucek RJ Jr, Boerth R\&, Bender $H W$. Abnormalities of right ventricular fun $\frac{8}{2}$ tion following Mustard's operation for transpositiog 
of the great arteries. Circulation 1975;52:678-84.

14 Benson LN, Bonet J, McLaughlin P, et al. Assessment of right ventricular function during supine bicycle exercise after Mustard's operation. Circulation 1982;65:1052-8.

15 Murphy JH, Barlai-Kovach MM, Mathews RA, et al. Rest and exercise right and left ventricular function late after the Mustard operation: assessment by radionuclide ventriculography. Am J Cardiol 1983: 51:1520-5.

16 Currie PJ, Kelly MJ, McKenzie A, et al. Oral betaadrenergic blockade with metoprolol in chronic severe dilated cardiomyopathy. J Am Coll Cardiol 1984;3:203-9.

17 Hurwitz RA, Caldwell RL, Girod DA, Mahoney L, Brown J, King H. Ventricular function in transposition of the great arteries: evaluation by radionuclide angiocardiography. Am Heart J 1985;110:600-5.

18 Parrish MD, Graham TP Jr, Bender HW, Jones JP,
Patton J, Partain CL. Radionuclide angiographic evaluation of right and left ventricular function during exercise after repair of transposition of the great arteries. Circulation 1983;67:178-82.

19 Benson LN, Burns R, Schwaiger M, et al. Radionuclide angiographic evaluation of ventricular function in isolated congenitally corrected transposition of great arteries. Am J Cardiol 1986;58:319-24.

20 Bonow RO, Rosing DR, McIntosh CL, et al. The natural history of asymptomatic patients with aortic regurgitation and normal left ventricular function. Circulation 1983;68:509-17.

21 Del Torso S, Kelly MJ, Kalff V, Venables AW. Radionuclide assessment of ventricular contraction at rest and during exercise following the Fontan procedure for either tricuspid atresia or single ventricle. Am J Cardiol 1985;55:1127-32.

22 Trusler GA. The Mustard procedure: a commentary. Ann Thorac Surg 1987;43:570-1. 